\title{
Management of a giant aortic root aneurysm in a young patient with Marfan syndrome: a case report
}

\author{
Jiayu Shen ${ }^{\dagger}$, Changping Gan ${ }^{\dagger}$, R. D. T. Rajaguru, Dou Yuan and Zhenghua Xiao ${ }^{*}$
}

\begin{abstract}
Introduction: Marfan syndrome (MFS) is a common heritable connective tissue disease involving multiple organs. Even though the clinical manifestations of MFS can be various, aortic root aneurysm is estimated as one of the most serious complications. We herein describe an individualized treatment decision-making process for a 23-yearold male with MFS, suffering from a giant but stable aortic root aneurysm which is extremely rare at his age.

Case: The patient, a 23-year-old male with a family history of MFS, presented to our cardiovascular department because of progressive exertional chest distress, fatigue and occasional precordial pain. Physical examinations revealed $190.5 \mathrm{~cm}$ of height, high myopia, and a diastolic murmur at the aortic valve area. Laboratory examinations for systemic vasculitis and infectious diseases were negative. Transthoracic echocardiography and enhanced thoracic computed tomography (CT) scan revealed the existence of a giant aortic root aneurysm $125.1 \mathrm{~mm}$ in short-axis), severe aortic valve regurgitation, cardiac dilatation ( $L V ; 99 \mathrm{~mm}$ in diastolic diameter) and a poor ejection fraction (EF; 18\%). Considering the risk of rupture or dissection of the dilated aortic root, we performed Bentall procedure based on the results of multidisciplinary team discussion and intraoperative exploration. Postoperative thoracic CT scan revealed a normal sized reconstructed aortic root, and the patient was discharged uneventfully 7 days later.
\end{abstract}

Conclusion: It is extremely rare to report such a giant aortic root aneurysm in a young patient. In the treatment decision-making process, the patient's specific situation should be taken into consideration. A mechanical Bentall procedure seems to be an acceptable option for some selected cases.

Keywords: Aortic aneurysm, Cardiac surgery, Dilated aortic root, Marfan syndrome

\section{Introduction}

Marfan syndrome (MFS) is an autosomal dominant disorder of connective tissues, which is primarily associated with the mutation of $\mathrm{FBN}-1$ gene on chromosome 15q21 encoding fibrillin-1, an essential glycoprotein in the extracellular matrix [1]. Aortic root aneurysm and ectopia lentis are considered as the cardinal features of MFS [2]. Indeed, it is the progressive dilation of the

\footnotetext{
* Correspondence: xiaozhenghua@wchscu.cn

${ }^{\dagger}$ Jiayu Shen and Changping Gan contributed equally to this work. Department of Cardiovascular Surgery, West China Hospital of Sichuan University, No.37 Guo Xue Alley, Chengdu 610041, Sichuan, China
}

aorta leading to aortic rupture or dissection that affects the prognosis. Meanwhile, aortic regurgitation secondary to aortic root dilation leads to ventricular volume overload, left ventricular dilation and eventually cardiac function impairment [3]. In order to reduce the risk of aortic dissection or secondary cardiac dysfunction, replacement of the dilated aortic root with a valved conduit has remained as the mainstay treatment strategy, whereas it may be met with anticoagulation-related complications and/or limited durability [4]. In recent years, with the deepening understanding of the anatomical structure of the aortic root and the increasing regard

(c) The Author(s). 2020 Open Access This article is licensed under a Creative Commons Attribution 4.0 International License, which permits use, sharing, adaptation, distribution and reproduction in any medium or format, as long as you give appropriate credit to the original author(s) and the source, provide a link to the Creative Commons licence, and indicate if changes were made. The images or other third party material in this article are included in the article's Creative Commons. licence, unless indicated otherwise in a credit line to the material. If material is not included in the article's Creative Commons licence and your intended use is not permitted by statutory regulation or exceeds the permitted use, you will need to obtain permission directly from the copyright holder. To view a copy of this licence, visit http://creativecommons.org/licenses/by/4.0/ The Creative Commons Public Domain Dedication waiver (http://creativecommons.org/publicdomain/zero/1.0/) applies to the data made available in this article, unless otherwise stated in a credit line to the data. 
to long-term prognosis, valve-sparing operations have become a promising treatment strategy for patients suffering from aortic root aneurysm. Its application, however, is still restricted in some specific conditions, such as the significantly dilated aortic annulus and severely damaged aortic valve [5]. We herein present our experience in managing a young MFS patient with a giant aortic root aneurysm by tailoring an individualized surgical regimen on the premise of a comprehensive perioperative assessment.

\section{Case}

A 23-year-old male presented to our cardiovascular department with progressive exertional chest distress and fatigue for over one year. One month before the admission, the patient experienced novo occasional precordial pain in addition to the presenting symptoms. On admission, physical examinations revealed heart rate of 96 beats/minute with a sinus rhythm, blood pressure of 130/55 $\mathrm{mmHg}$, high myopia, $190.5 \mathrm{~cm}$ of height and a diastolic murmur at the aortic valve area. Laboratory examinations for systemic vasculitis and infectious diseases were unremarkable. Transthoracic echocardiography (TTE) demonstrated a giant aortic root aneurysm, an enlarged left ventricle $(L V ; 99 \mathrm{~mm}$ in end-diastolic dimension) and severe aortic regurgitation combined with extremely poor ejection fraction (EF; 18\%). No mitral regurgitation or tricuspid regurgitation were observed. Enhanced thoracic CT scan performed with a 16detector row confirmed the extensive dilated aortic root aneurysm, bulging against the sternum (Fig. $1 a$ and b, asterisks; $125.1 \mathrm{~mm}$ in short-axis), while the morphology of the distal of ascending aorta and descending aorta were normal (30 mm in short-axis). Three-dimensional enhanced CT scan revealed that the aortic root aneurysm is like a "bulging balloon" (Fig. 1c, asterisk). According to the patient's self-statement, both of his grandpa and father died from aortic dissection caused by MFS, and he was identified with FBN1 mutations when he was a child. Unfortunately, the patient was lost to follow up owing to his poor compliance. Taken together, this patient was diagnosed with MFS based on the Revised Ghent Criteria [2].

The cardiac dysfunction of this patient was improved after receiving cardiotonic and diuretic therapy. After multidisciplinary discussion, surgical intervention, instead of continuously medical therapy, was accepted as reasonable and life-saving, in consideration of the risk of rupture/dissection of the aortic root aneurysm and deteriorating cardiac function. The specific surgical approaches should be decided based on the intraoperative exploration results. Elective femoral arteriovenous cardiopulmonary bypass was performed to avoid unexpected rupture of the giant aneurysm during median sternotomy. Following pericardiotomy, the aneurysm almost completely filled the pericardial cavity and compressed the right atrial and the pulmonary artery (Fig. 2a, asterisk). After clamping the aorta and opening the aneurysm sac, we observed a tricuspid aortic valve with multiple fenestrations occurring towards the commissures, a torn leaflet and a dilated aortic annulus which was measured over $38 \mathrm{~mm}$. Further exploration verified the morphology of mitral valve was normal. Considering the patient's poor cardiac function with bad aortic valvular condition and he may not be able to tolerate time-consuming procedures, we decided to perform Bentall procedure with a $28-\mathrm{mm}$ conduit composite a $25-\mathrm{mm}$ mechanical aortic valve (Fig. 2b). Postoperative three-dimensional enhanced CT scan revealed a normal sized reconstructed aortic root (Fig. 2c) and pre-discharge TEE examination confirmed the patient's EF was improved to $40 \%$ and the LV enddiastolic dimension was reduced to $59 \mathrm{~mm}$. The patient received anticoagulation therapy and he was discharged uneventfully 7 days later. Regular follow up was required

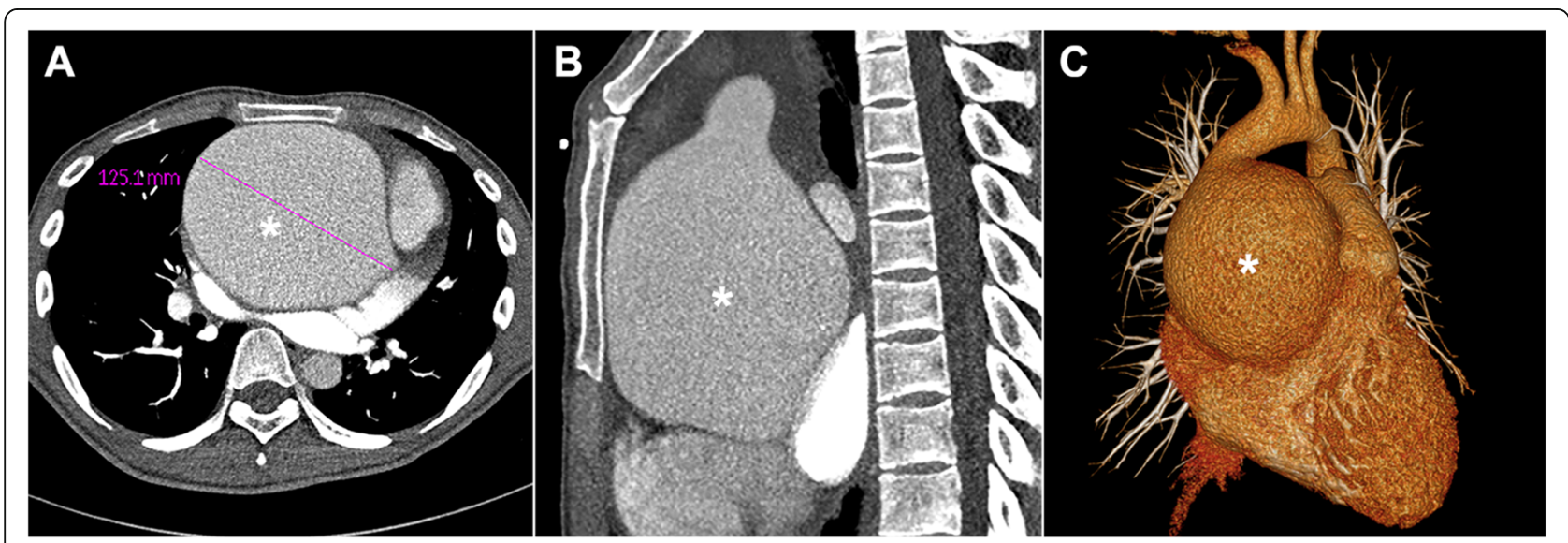

Fig. 1 Results of preoperative imaging examinations: $\mathbf{a}$ and $\mathbf{b}$ Transverse view and sagittal view of enhanced thoracic computed tomography scan demonstrated the size of the aneurysm, respectively; c Three-dimensional enhanced computed tomography scan showed that the aortic root aneurysm is like a "bulging balloon"; *, aortic root aneurysm 


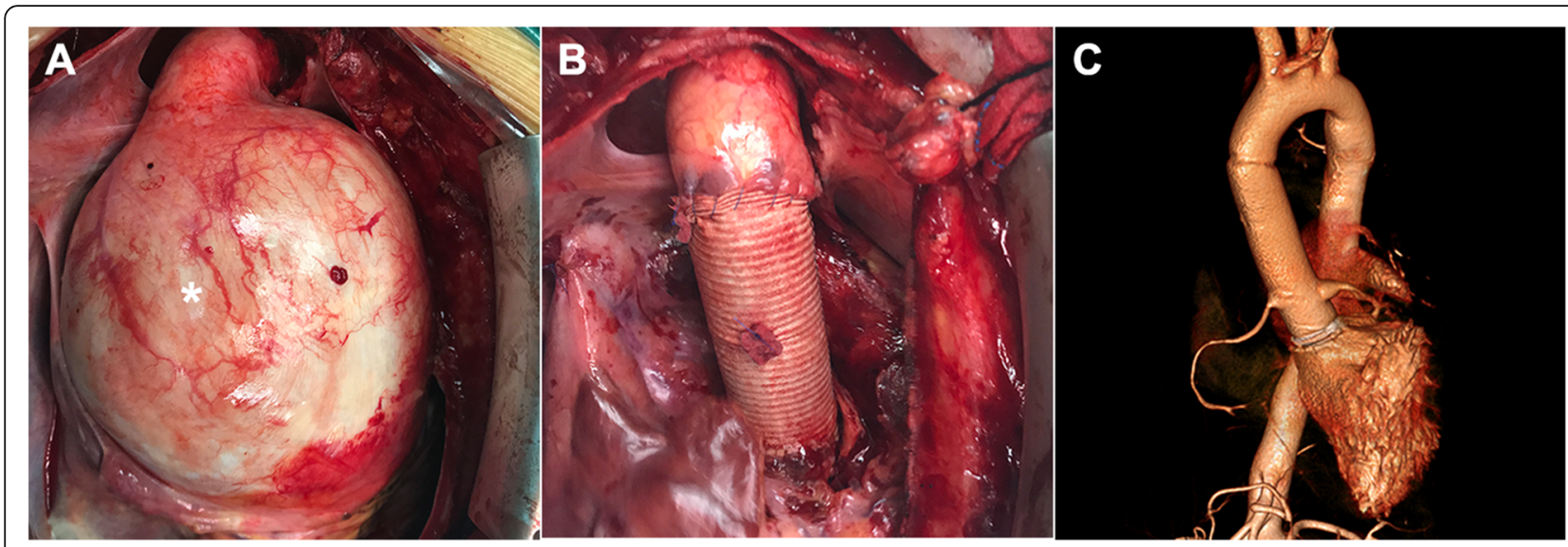

Fig. 2 Results of intraoperative exploration and postoperative imaging examination: a The aortic root aneurysm compressed the right atrial and the pulmonary artery; $\mathbf{b}$ The aortic root aneurysm was removed after Bentall procedure; $\mathbf{c}$ Three-dimensional enhanced computed tomography scan of pre-discharge showed a normal sized aortic root

to reduce the risk of anticoagulation-related complications. Moreover, enhanced thoracic CT scan and echocardiography examination were required at least once per year to monitor the morphology of valved conduit and the cardiac function and valvular condition of this patient.

\section{Discussion}

MFS is a common autosomal dominant genetic disorder caused by FBN1 mutations [6]. The reported prevalence varies from 1 to 3 per 10,000 individuals, depending on the diagnostic criteria and ethnicity, while no sex predilection is apparent in MFS [7, 8]. Although this monogenic connective tissue disorder generally segregates as a dominant trait in families, novo mutations are responsible for nearly $25 \%$ of cases [9]. Even though MFS affects various systems including skeletal, oclar and cardiovascular systems, the latest nosology emphasizes on the alterations in the cardiovascular system which is the most detrimental phenotype [2]. Indeed, dissection or rupture of the dilated aortic root which is seen in nearly three quarters of patients with MFS is the predominant cause of mortality in these cases, with a peak incidence in the third and fourth decades of life $[3,6,9]$.

Usually, MFS patients are asymptomatic when the dilated aorta remains stable. However, the dilation rate of the aorta is heterogeneous and cannot be predicted. Although the risk of type A dissection clearly increases with the increasing aortic root diameter, it can also occur even in patients with mild aortic dilation [5], just like an unstable deadly "bulging balloon". Moreover, if the dilation involves the aortic annulus and aortic valve is anatomically changed, cardiac dysfunction secondary to valvular regurgitation would be the dominant clinical feature. In this patient, even though the aortic root aneurysm has dilated to such rare giant scale, it remained stable and the clinical symptoms were mainly due to cardiac dysfunction secondary to aortic regurgitation and an enlarged left ventricle.

Early screening and establishment of the diagnosis of aortic aneurysm in patients with a family history of MFS is critical since prophylactic intervention can reduce the risk of aortic dissection and rupture effectively, which requires effective screening methods. As most of the early stage patients are asymptomatic, the aortic aneurysm is usually found occasionally during a routine X-ray, which shows a widened mediastinum [4]. Furthermore, echocardiographic assessment can provide us with detailed information regarding the morphological features of the left ventricle, aortic annulus, aortic sinuses and ascending aorta in multiple views and dynamic videos in evaluating aortic valve morphology and the mechanism of aortic insufficiency $[10,11]$. Due to its convenience and safety, echocardiography has been widely used in young individuals who require repetitive imaging and long-term followup. However, echocardiographic evaluation alone cannot offer information on adjacent structures or the involvement of aortic branches. In this case, furthermore, we performed an enhanced thoracic CT scan to visualize the main aortic branches and measure the extent and size of the aneurysm accurately.

Once the diagnosis of aortic aneurysm has been confirmed in patients with MFS, intense physical activity such as weightlifting should be avoided due to the potential risk inducing rupture or dissection of the aortic aneurysm [12] Meanwhile, regular follow-up is necessary. Concurrently, conservative management is aimed at decreasing the heart rate and lowering the blood pressure to reduce the hemodynamic stress on the proximal aorta [13]. $\beta$-adrenergic receptor antagonists, including propranolol, atenolol and nebivolol [14-16] have become the most prescribed medications for MFS patients as they might decrease the aortic dilation rate [17]. 
Losartan, one of the angiotensin II receptor 1 blockers (ARBs), is useful in inhibiting the dilation of the aorta as it was recently discovered that angiotensin II is involved in MFS pathophysiological process [18]. However, more clinical trials are required to verify the ability of ARBs to interfere with the MFS pathology. Even though several novel therapeutic strategies are under investigation, the goal of precision medicine is laborious to achieve [19]. Surgical intervention remains as the gold standard treatment strategy for aneurysm in MFS.

Surgical treatment should be considered in MFS patients who have aortic root dilatation with a maximal diameter $\geq 50 \mathrm{~mm}$ [20]. If there are additional risk factors including family history of aortic dissection, severe aortic regurgitation, desire for pregnancy, systemic hypertension and/or aortic size increase $>3 \mathrm{~mm} /$ year, surgical intervention is recommended when maximal aortic diameter $\geq 45 \mathrm{~mm}$ [20]. Bentall procedure (composite replacement of the aortic valve and dilated ascending aorta combined with coronary artery reimplantation) has become a low-risk and durable operation with 5- and 10-year survival rates of $84 \%$ and $75 \%$, respectively [21]. Meanwhile, aortic valve-sparing operations such as David's procedure (reimplantation of the aortic valve) and Yacoub's procedure (remodeling of the aortic root) in young patients with aortic aneurysm have represented promising treatment strategies in recent years [22]. Even though Yacoub's procedure has been reported to be inappropriate for patients with Marfan syndrome because of the significant aortic insufficiency and reoperation rate [23], David's procedure shows excellent outcomes [24]. In this case, the significant dilation of the aortic annulus caused structural damage to the aortic cusps and multiple fenestrations were detected around commissures. While David's procedure with an external annuloplasty band can correct the dilated aortic annulus, this outcome may not last for long [25]. More importantly, in this case, our patient is not a suitable candidate for time-consuming valve-sparing procedure in considering his poor cardiac function. As the body surface area of this patient was measured as $1.99 \mathrm{~m}^{2}$ and the morphology of the distal of ascending aorta was normal, we finally decided to perform Bentall procedure for this patient with a 28-mm conduit composite a $25-\mathrm{mm}$ mechanical aortic valve in order to balance the risk of prosthesis-patient mismatch and the suitability of grafted conduit.

Based on our limited experience learned from this case, we suggested that the management options for MFS patients with aortic root aneurysm should depend on the valvular anatomical morphology and patients' overall health status. For patients with anatomically normal valve combined with acceptable cardiac function, valve-sparing operation should be attempted as it reduces the risk of thromboembolism, hemorrhage and infective endocarditis, especially in young patients. Otherwise, Bentall procedure should be performed, and lifelong anticoagulation therapy is mandatory in young patients.

\section{Conclusion}

The treatment decision-making process should depend on the patients' specific situations. Our practice indicates that the mechanical Bentall procedure remains a valuable approach in some selected patients.

\section{Abbreviations \\ CT: Computed tomography; EF: : Ejection fraction; MFS: : Marfan syndrome; TTE: : Transthoracic echocardiography; ARBs: : Angiotensin II receptor 1 blockers}

\section{Acknowledgements \\ Not applicable}

\section{Authors' contributions}

All authors participated in the management of the patient in this case report. JYS drafted the manuscript. TR revised the manuscript. DY and CPG wrote part of discussion and introduction. ZHX supervised the case and also supervised the writing of the manuscript. All authors read and approved the manuscript.

\section{Funding}

This study was supported by grants from the National Natural Science Foundation of China No. 81500213 and No. 81370413; Sichuan Science and Technology program: 2018SZ0384. The funders had no role in the study design, data collection and analysis, writing of the manuscript, and decision to submit the article for publication.

\section{Availability of data and materials}

All data generated or analyzed during this study are included in this published article.

Compliance with ethical standard

Ethics approval and consent to participate Not applicable.

\section{Consent for publication}

Written informed consent was obtained from the patient for publication of this Case report and any accompanying images. A copy of the written consent is available for review by the editor of this journal.

\section{Competing interests}

The authors declare that they have no competing interests.

Received: 16 July 2020 Accepted: 8 September 2020

Published online: 24 September 2020

\section{References}

1. Robinson PN, Arteaga-Solis E, Baldock C, Collod-Beroud G, Booms P, De Paepe A, Dietz HC, Guo G, Handford PA, Judge DP, et al. The molecular genetics of Marfan syndrome and related disorders. J Med Genet. 2006; 43(10):769-87.

2. Loeys BL, Dietz HC, Braverman AC, Callewaert BL, De Backer J, Devereux RB, Hilhorst-Hofstee $Y$, Jondeau G, Faivre L, Milewicz DM, et al. The revised Ghent nosology for the Marfan syndrome. J Med Genet. 2010;47(7):476-85.

3. Ramachandra CJ, Mehta A, Guo KW, Wong P, Tan JL, Shim W. Molecular pathogenesis of Marfan syndrome. Int J Cardiol. 2015;187:585-91.

4. David TE. Surgical treatment of ascending aorta and aortic root aneurysms. Prog Cardiovasc Dis. 2010;52(5):438-44.

5. Baumgartner H, Bonhoeffer P, De Groot NM, de Haan F, Deanfield JE, Galie N, Gatzoulis MA, Gohlke-Baerwolf C, Kaemmerer H, Kilner P, et al. ESC 
Guidelines for the management of grown-up congenital heart disease (new version 2010). Eur Heart J. 2010;31(23):2915-57.

6. Patel HJ, Deeb GM. Ascending and arch aorta: pathology, natural history, and treatment. Circulation. 2008;1 18(2):188-95.

7. Franken $R$, den Hartog AW, van de Riet L, Timmermans J, Scholte AJ, van den Berg MP, de Waard V, Zwinderman AH, Groenink M, Yip JW, et al. Clinical features differ substantially between Caucasian and Asian populations of Marfan syndrome. Circ J. 2013;77(11):2793-8.

8. Groth KA, Hove H, Kyhl K, Folkestad L, Gaustadnes M, Vejlstrup N, Stochholm K, Ostergaard JR, Andersen NH, Gravholt CH. Prevalence, incidence, and age at diagnosis in Marfan Syndrome. Orphanet J Rare Dis 2015;10:153

9. Judge DP, Dietz HC. Marfan's syndrome. Lancet. 2005;366(9501):1965-76. .

10. Evangelista A. Imaging aortic aneurysmal disease. Heart. 2014;100(12): 909-15.

11. Evangelista A, Flachskampf FA, Erbel R, Antonini-Canterin F, Vlachopoulos C, Rocchi G, Sicari R, Nihoyannopoulos P, Zamorano J, Pepi M, et al. Echocardiography in aortic diseases: EAE recommendations for clinical practice. Eur J Echocardiogr. 2010;11(8):645-58.

12. Cheng A, Owens D. Marfan syndrome, inherited aortopathies and exercise: what is the right answer? Heart. 2015;101(10):752-7.

13. Radke RM, Baumgartner H. Diagnosis and treatment of Marfan syndrome: an update. Heart. 2014;100(17):1382-91.

14. Koo HK, Lawrence KA, Musini VM. Beta-blockers for preventing aortic dissection in Marfan syndrome. Cochrane Database Syst Rev. 2017;11: Cd011103.

15. Keane MG, Pyeritz RE. Medical management of Marfan syndrome. Circulation. 2008;117(21):2802-13.

16. Gambarin Fl, Favalli V, Serio A, Regazzi M, Pasotti M, Klersy C, Dore R, Mannarino S, Vigano M, Odero A, et al. Rationale and design of a trial evaluating the effects of losartan vs. nebivolol vs. the association of both on the progression of aortic root dilation in Marfan syndrome with FBN1 gene mutations. J Cardiovasc Med. 2009;10(4):354-62.

17. Engelfriet $P$, Mulder $B$. Is there benefit of beta-blocking agents in the treatment of patients with the Marfan syndrome? Int J Cardiol. 2007;114(3): $300-2$.

18. Perrucci GL, Rurali E, Gowran A, Pini A, Antona C, Chiesa R, Pompilio G, Nigro P. Vascular smooth muscle cells in Marfan syndrome aneurysm: the broken bricks in the aortic wall. Cellular and molecular life sciences: CMLS. 2017;74(2):267-77.

19. Rurali E, Perrucci GL, Pilato CA, Pini A, Gaetano R, Nigro P, Pompilio G. Precise therapy for thoracic aortic aneurysm in marfan syndrome: a puzzle nearing its solution. Prog Cardiovasc Dis. 2018;61(3-4):328-35.

20. Falk V, Baumgartner $\mathrm{H}$, Bax JJ, De Bonis M, Hamm C, Holm PJ, lung B, Lancellotti P, Lansac E, Munoz DR, et al. 2017 ESC/EACTS Guidelines for the management of valvular heart disease. Eur J Cardiothorac Surg . 2017;52(4): 616-64

21. Gott VL, Greene PS, Alejo DE, Cameron DE, Naftel DC, Miller DC, Gillinov AM, Laschinger JC, Pyeritz RE. Replacement of the aortic root in patients with Marfan's syndrome. N Engl J Med. 1999;340(17):1307-13.

22. David TE, Feindel CM, Webb GD, Colman JM, Armstrong S, Maganti M. Long-term results of aortic valve-sparing operations for aortic root aneurysm. J Thorac Cardiovasc Surg. 2006;132(2):347-54.

23. David TE, David CM, Manlhiot C, Colman J, Crean AM, Bradley T. Outcomes of aortic valve-sparing operations in Marfan syndrome. J Am Coll Cardiol. 2015;66(13):1445-53.

24. Shrestha ML, Beckmann E, Abd Alhadi F, Krueger H, Meyer-Bockenkamp F, Bertele S, Koigeldiyev N, Kaufeld T, Fleissner F, Korte W, et al. Elective David I procedure has excellent long-term results: 20-year single-center experience. Ann Thorac Surg. 2018;105(3):731-8.

25. David TE. Aortic valve sparing in different aortic valve and aortic root conditions. J Am Coll Cardiol. 2016;68(6):654-64.

\section{Publisher's Note}

Springer Nature remains neutral with regard to jurisdictional claims in published maps and institutional affiliations.

\section{Ready to submit your research? Choose BMC and benefit from:}

- fast, convenient online submission

- thorough peer review by experienced researchers in your field

- rapid publication on acceptance

- support for research data, including large and complex data types

- gold Open Access which fosters wider collaboration and increased citations

- maximum visibility for your research: over $100 \mathrm{M}$ website views per year

At BMC, research is always in progress.

Learn more biomedcentral.com/submissions 